\title{
Acupressure Therapy as Alternative Treatment on Cancer-Related Fatigue in Cancer Patients
}

\author{
Yesiana Dwi Wahyu Werdani ${ }^{1}$ \\ ${ }^{1}$ Nursing Faculty, Universitas Katolik Widya Mandala Surabaya \\ Email: ywerdani@yahoo.com
}

Received 14 November 2018; Accepted 1 February 2019; Published 22 May 2019

\begin{abstract}
Cancer progressively affects organ function and causes the neurophysiological changes in skeletal muscle, leading to cancer-related fatigue. The impact of cancer related fatigue affect of physical condition, psychology, social and reduce the quality of life of patients. Acupressure therapy can stimulate the improvement of local microcirculation and increasing physical performance by suppressing molecules that trigger fatigue in the blood. The purpose of this study determine the influence of acupressure therapy on cancer-related fatigue in cancer patients. The design used was a pre-experiment one group pre-test post-test design approach. The populations were cancer patients living at the Indonesian Cancer Foundation East Java Branch. Samples were 30 cancer patients taken by purposive technique based on inclusion criteria. The instrument was the Brief Fatigue Inventory which has been tested for validity and reliability. Acuressure therapy is given to acupoint C6, GB20, P6, Li4, Li11, Sp 6, St 36, 2 times per week for 4 weeks. Statistics was verified with Wilcoxon Sign Rank Test $p<0.05$. Result showed the effect of acupressure therapy on cancer related fatigue $p=0.000$. Accupressure therapy can activate acupoint points on the meridians, stimulating myelin nerves in the muscles and impulses into the central nervous system and can facilitate the reduction of complaints of fatigue or other symptoms of pain in parts of the body.
\end{abstract}

Keywords: Acupoint, acupressure therapy, cancer related fatigue

Copyright () 2019 STIKes Surya Mitra Husada

All right reserved.

This is an open-acces article distributed under the terms of the Creative Commons AttributionShareAlike 4.0 International License.

\section{INTRODUCTION}

Cancer progressively affect several organ functions and causes the neurophysiological changes in skeletal muscle, abnormal production of certain substances such as cytokines, inhibit metabolism in normal muscle function and can cause cancer-related fatigue (CRF) (Ryan, et al., 2007). Fatigue is a very subjective multidimensional experience involves physical fatigue, decreased need for activity, decreased motivation and mental fatigue (Ahlberg, Ekman, Gaston-Johansson, \& Mock, 2003). CRF can progressively disrupt the fulfillment of the patient's basic daily needs and affect the level of patient dependence on caregiver. Severe fatigue is experienced by $50 \%$ of cancer patients and they had a caregiver dependency level of $86.6 \%$ with the majority was the severe dependence. (Werdani, 2018). Based on the results of the preliminary survey in 2017 at Indonesian Cancer Foundation East Java Branch, cancer patients with CRF only received pharmacological treatment from the hospital and they only reduced their activities when they felt fatigue (Werdani, 2018).

The prevalence of cancer in Indonesia reaches 4.9 per mile, with the largest number being women, which is 2.9 per mile and the majority is in urban areas, namely 2.06 percent. The most cancer 
management is surgery reached $61.8 \%$, chemotherapy $24.9 \%$, radiation $17.3 \%$ and other therapies 24.1\% (Badan Penelitian dan Pengembangan Kesehatan, 2018).

Cancer and cancer treatment causes defects in the mechanism for regenerating Adenotriphospat (ATP) in skeletal muscle, thereby reducing the ability to perform mechanical activity (Ryan, et al., 2007). Cancer treatment causes an increasing serotonin hormone, it can decrease in somatomotor drive, modification of the function of the hypothalamic-pituitary-adrenal axis (HPA), and decreased sensation of capacity to do physical work. Fatigue is often major complaints in patients were diagnosed with cancer. The significant fatigue occurred in breast cancer patients in the amount of $40 \%, 33 \%$ in colorectal cancer patients and patients with prostate cancer 17\% (Jones, et al., 2016).

One of the palliative treatment that can be given to cancer patients with CRF is acupressure therapy. It is a technique physical suppression at the point of acupoints using hands, elbows, or a device, to stimulate sensory nerve cells and the hypothalamus function (Zick, et al., 2012). Acupressure therapy in various types of cancer can reduce persistent cancer-related fatigue (PCRF) (Zick, et al., 2012). Acupressure treatment reduced 34\% in CRF complaints in cancer patients (Lovejoy, 2016). This study examined the effect of acupressure therapy on cancer-related fatigue in cancer patients. The purpose of this study determine the influence of acupressure therapy on cancer-related fatigue in cancer patients.

\section{MATERIALS AND METHODS}

This study used pre experimental design with one group pre-test post-test design. The sample were cancer patients at Indonesian Cancer Foundation East Java Branch which amounted to 30 people, taken by purposive sampling technique. This study used the Brief Fatigue Inventory (BFI) that has been tested for validity and reliability with the $\mathrm{R}$ value $0.657-0.897$ and Cronbach alpha result being 0.867 . It means that the instrument was valid and reliable for measuring cancer-related fatigue. This study has been carried out the ethical tests and stated ethical conduct. Explanation of the research procedure, purposes, advantages and risk, informed to participants and signing the informed consent who agreed as participants. All participants fullfilled the BFI questionnaire as a pre test, continued by treatment of acupressure therapy $2 \mathrm{x}$ a week with acupoint pressure in C6, GB20, P6, Li4, Li11, Sp 6, St 36, it conducted for 4 weeks. Accupressure therapy was carried out by certified therapist who had experience implementing acupressure. After the treatment period is completed, post test is done by giving more BFI questionnaire. After the data collected, the researcher performs coding, scoring and tabulation. Analyzed used the Wilcoxon Signed Rank Test with $\mathrm{p}<0.05$. 


\section{RESULTS}

Table 1. General data of Participants at the Indonesian Cancer Foundation East Java Branch, June 2018

\begin{tabular}{cccc}
\hline General Data & Categories & $\begin{array}{c}\text { Frequency } \\
\text { (persons) }\end{array}$ & $\begin{array}{c}\text { Percentage } \\
(\%)\end{array}$ \\
\hline \multirow{2}{*}{ Aged } & $36-45$ years & 4 & 13.4 \\
& $46-55$ years & 13 & 43.3 \\
Sex & $56-65$ years & 13 & 43.3 \\
& Female & 23 & 76.7 \\
Time of diagnosed with cancer & Male & 7 & 23.3 \\
& < years & 3 & 10 \\
& $1-3$ years & 16 & 53.3 \\
& $4-6$ years & 5 & 16.7 \\
& $>6$ years & 6 & 20 \\
\hline \multirow{3}{*}{ Cancer Stage } & I & 1 & 3.3 \\
& II & 10 & 33.3 \\
& III & 2 & 56.7 \\
& IV & 12 & 6.7 \\
\hline \multirow{3}{*}{ Cancer Types } & Breast Cancer & 10 & 40 \\
& Nasopharynx Cancer & 1 & 20 \\
& Servical Cancer & 1 & 33.4 \\
& Thyroid Cancer & 6 & 3.3 \\
\hline \multirow{2}{*}{ Undergoing Therapy } & Colon Cancer & 14 & 46.7 \\
& Surgery + Chemotherapy & 10 & 33.3 \\
\hline
\end{tabular}

The majority of participants (43.3\%) aged 46 - 55 years and $56-65$ years, and dominated by female $(76.7 \%)$. Most of the participants $(53.3 \%)$ had cancer for $1-3$ years with the highest stage (56.7\%) was stage III. The majority of participants (40\%) were breast cancer and chemoradiotherapy was the most undergoing theraphy $(46.7 \%)$.

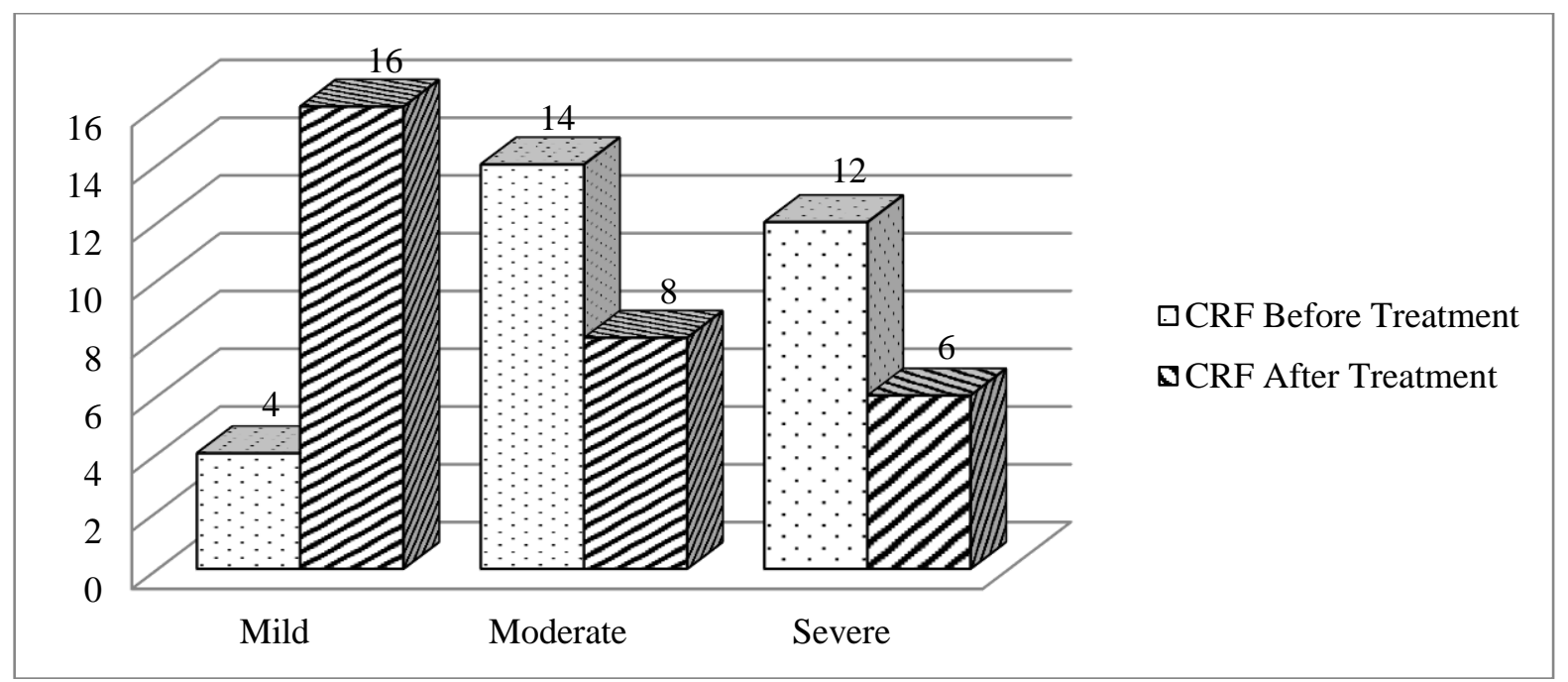

Figure 1. Cancer-Related Fatigue Before and After Acupressure Therapy at the Indonesian Cancer Foundation East Java Branch, June 2018. 
Prior to treatment, the majority of participants (47\%) had moderate level of CRF, 12 people (40\%) had severe CRF, and only 4 people (13\%) had mild CRF. However, after the treatment of acupressure therapy for 4 weeks, there was a change of condition, the majority of CRF had at mild level (53\%), 8 people (27\%) had moderate CRF and only 6 people (20\%) had severe CRF.

Table 2. Descriptive statistic of acupressure therapy, The Indonesian Cancer Foundation East Java Branch, June 2018

\begin{tabular}{lllcc}
\hline & & $\mathrm{N}$ & Mean Rank & Sum of Ranks \\
\hline \multirow{3}{*}{ CRFPost - CRFPre } & Negative Ranks & $0^{\mathrm{a}}$ & .00 & .00 \\
\cline { 2 - 5 } & Positive Ranks & $18^{\mathrm{b}}$ & 9.50 & 171.00 \\
\cline { 2 - 5 } & Ties & $12^{\mathrm{c}}$ & & \\
\cline { 2 - 5 } & Total & 30 & & \\
\hline
\end{tabular}

The majority of CRF levels got better from moderate level to mild level and from severe level to moderate level, the total of it were 18 people $(60 \%)$. As many as 12 people $(40 \%)$ in remained condition.

Table 3. The Wilcoxon Sign Ranks Test of acupressure therapy, The Indonesian Cancer Foundation East Java Branch, June 2018

\begin{tabular}{c|c}
\hline & CRFPost - CRFPre \\
\hline $\mathrm{Z}$ & $-4.243^{\mathrm{a}}$ \\
\hline Asymp. Sig. (2-tailed) & .000 \\
\hline
\end{tabular}

The significancy of statistic test was $0.000(\mathrm{p}<0.05)$, it means that acupressure therapy had positive effect to reduce CRF in cancer patients.

\section{DISCUSSION}

\section{Cancer Related Fatigue Before Acupressure Therapy}

In this study found that $47 \%$ participants had a moderate level of CRF, $40 \%$ had severe levels of CRF and minority of participants $13 \%$ had mild CRF. In this condition the participants complained that fatigue was experienced every day and could interfere their daily activities, eventhough made participants become bad mood throughout the day and causes the participant's communication disturbed with others. The participants also felt the feeling of exhaustion, it caused they are unable to enjoy their lives.

The moderate and severe levels of CRF found in the study can be related to the stage of cancer stage, of which $56.7 \%$ had in stage III and $6.7 \%$ had in stage IV. Stage III of cancer has characteristics of that cancer cells that have spread to the tissue around these cancer cells, whereas stage IV of cancer is a cancer cell that has metastatic to other parts of the body outside the cancer cell (French National Cancer Institute, 2010). Medical treatments to prevent the cancer cell metastatic are chemotherapy, radiation, surgery, chemoradiotherapy (Mokhtari, et al., 2017). In this study all participants were given chemoradiotherapy (46.7\%). Radiotherapy and chemotherapy can trigger oxidative stress which not only attacks the target tissue, but also on healthy tissue, it causes toxicity and dysfunction of all organs (Gilliam \& St. Clair, 2011). 449 cancer patients reported fatigue as the most common side effect, followed by diarrhea and constipation (Pearce, et al., 2017). Another research also stated that of 100 cancer patients 95\% experienced weakness and fatigue 90\% (Aslam, et al., 2014). Severe fatigue is more common in chemotherapy (98.3\%), and concurrent radiation chemotherapy (78.57\%) compared 
to radiotherapy which tends to cause moderate fatigue (45\%) (Karthikeyan, Jumnani, Prabhu, Manoor, $\&$ Supe, 2012).

\section{Cancer Related Fatigue After Acupressure Therapy}

Based on the results of this study, it was found that there was a change condition that the majority of CRF was at a mild level (53.3\%), moderate level decreased to $26.7 \%$ even at the severe level there were only $20 \%$. Acupressure therapy can improve the level of fatigue and affecting the working system of the brain by pressing on the hand/thumb at certain acupoints to balance physiological energy flow (Tournaire \& Theau-Yonneau, 2007). In this study the acupoints points used were points C6, Li4, Li11, Sp 6, St 36, GB 20 and P6. These points are useful for reducing fatigue and increasing body energy (Mehta, Dhapte, Kadam, \& Dhapte, 2017). Acupressure on P3 acupoint given to chemotherapy patients can improve the patient's CRF condition (Hou, Zhou, $\mathrm{Wu}, \mathrm{Yu}, \& \mathrm{Hu}, 2017$ ). Comparasion between acupressure relaxation therapy, high-dose acupressure stimulation, and low-dose acupressure stimulation for 12 weeks showed that a significant decrease in fatigue in all treatment groups with a greater reduction occurring in the acupressure relaxation group (Zick, et al., 2011). 288 breast cancer patients given relaxation acupressure cause 66.2\% decreased fatigue (Zick, et al., 2016). Giving acupressure for 4 weeks in hemodialysis patients showed an improvement in the level of patient fatigue (Sabouhi, Kalani, Valiani, Mortazavi, \& Bemanian, 2013). Applied acupressure for breast cancer patients, the results of the severity of fatigue and depression improved (Zick, et al., 2012).

\section{Effect of Acupressure Therapy on Cancer Related Fatigue}

In this study the results showed that the majority of participants (60\%) experienced a positive change in CRF, a decrease in CRF levels in a better direction, $40 \%$ did not experience changes or were at the same level of CRF both before and after intervention. In the statistical test with the Wilcoxon Signed Rank Test, $p=0.000$ it means that there is an influence of acupressure therapy on cancer related fatigue. It caused by active manipulation at acupoints that are carried out routinely and continuously. The emphasis on acupressure points must be positioned along the meridian line. Meridian is a channel in the human body that maintain Qi. Each meridian is connected to various organs and tissues of the human body. Activation of certain points on the meridian can facilitate the reduction of complaints, symptoms or pain from other parts of the body (Andrews \& Dempsey, 2007). Based on the location of stimulation, pressure activates small myelin nerves in the muscle and passes stimulation of impulses to the central nervous system including the spinal cord, midbrain, hypothalamus and pituitary axis (Ezzo, Streitberger, \& Schneider, 2006). Acupressure in ST 36 and Li12 acupoints in 120 acute lymphoblastic leukemia patients after chemotherapy, caused a decrease in fatigue 1 hour after intervention (Bastani, Khosravi, Borimnejad, \& Arbabi, 2015). Acupressure mediates nitric oxide (NO) signals, to improve local microcirculation through cyclic guanosine monophosphate (cGMP). It helps in increasing physical performance by pressing molecules that trigger fatigue in the blood (Jou \& Ma, 2009). Acupressure in patients with hepatocellular carcinoma, the results showed that fatigue in the acupressure group were lower than in the control group (Lan, Lin, Chen, Lin, \& Wang, 2015). Acupressure which is selfmanaged for 6 weeks causes a significant reduction in depression and fatigue in patients with breast cancer (Mehling, et al., 2012). Performed GB 20 Fengchi acupoint stimulation could improve stiff neck, headache, dizziness, and fatigue (Ma, Chang, \& Lin, 2007).

\section{CONCLUSION}

Based on the results of this study, it can be concluded that cancer patients can experience CRF with various levels ranging from mild to severe, but by providing acupressure therapy as a an alternative treatment routinely and continuously can have a significant effect on the decrease in CRF to the lower level. 


\section{REFERENCE}

Ahlberg, K., Ekman, T., Gaston-Johansson, F., \& Mock, V. (2003). Assessment and management of cancerrelated fatigue in adults. The Lancet, 362(9384), 640-650. https://doi.org/10.1016/S0140.

Andrews, S., \& Dempsey, B. (2007). Acupressure \&amp; reflexology for dummies. Wiley. Retrieved from dari https://www.wiley.com/en-us/Acupressure+and+Reflexology+For+Dummies-p-9780470139424.

Aslam, M., S., Naveed, S., Ahmed, A., Abbas, Z., Gull, I., \& Athar, M., A. (2014). Side Effects of Chemotherapy in Cancer Patients and Evaluation of Patients Opinion about Starvation Based Differential Chemotherapy. Journal of Cancer Therapy 5(5), 817-822. https://doi.org/10.4236/jct.2014.58089.

Badan Penelitian dan Pengembangan Kesehatan. (2018). Hasil Utama Riskesdas 2018. Jakarta: Kementrian Kesehatan Republik Indonesia.

Bastani, F., Khosravi, M., Borimnejad, L., \& Arbabi, N. (2015). The effect of acupressure on cancer-related fatigue among school-aged children with acute lymphoblastic leukemia. Iranian journal of nursing and midwifery research, 20(5), 545-551. https://doi.org/10.4103/1735-9066.164508.

Ezzo, J., Streitberger, K., \& Schneider, A. (2006). Cochrane Systematic Reviews Examine P6 Acupuncture-Point Stimulation for Nausea and Vomiting. The Journal of Alternative and Complementary Medicine, 12(5), 489-495. https://doi.org/10.1089/acm.2006.12.489.

French National Cancer Institute. (2010). National Cancer Institute 2009 Activity Report. Boulogne-BillancourtFrance. Retrieved from dari www.e-cancer.fr.

Gilliam, L., A., A., \& St. Clair, D., K. (2011). Chemotherapy-Induced Weakness and Fatigue in Skeletal Muscle: The Role of Oxidative Stress. Antioxidants \& Redox Signaling, 15(9), 2543-2563. https://doi.org/10.1089/ars.2011.3965.

Hou, L., Zhou, C., Wu, Y., Yu, Y., \& Hu, Y. (2017). Transcutaneous electrical acupoint stimulation (TEAS) relieved cancer-related fatigue in non-small cell lung cancer (NSCLC) patients after chemotherapy. Journal of thoracic disease, 9(7), 1959-1966. https://doi.org/10.21037/jtd.2017.06.05.

Jones, J., M., Olson, K., Catton, P., Catton, C., N., Fleshner, N., E., Krzyzanowska, M., K., \& Howell, D. (2016). Cancer-related fatigue and associated disability in post-treatment cancer survivors. Journal of Cancer Survivorship, 10(1), 51-61. https://doi.org/10.1007/s11764-015-0450-2.

Jou, N.-T., \& Ma, S.-X. (2009). Responses of nitric oxide-cGMP release in acupuncture point to electroacupuncture in human skin in vivo using dermal microdialysis. Microcirculation (New York, N.Y. : 1994), 16(5), 434-443. https://doi.org/10.1080/10739680902915012.

Karthikeyan, G., Jumnani, D., Prabhu, R., Manoor, U., \& Supe, S. (2012). Prevalence of fatigue among cancer patients receiving various anticancer therapies and its impact on Quality of Life: A cross-sectional study. Indian Journal of Palliative Care, 18(3), 165. https://doi.org/10.4103/0973-1075.105686.

Lan, S.-C., Lin, Y.-E., Chen, S.-C., Lin, Y.-F., \& Wang, Y.-J. (2015). Effects of Acupressure on Fatigue and Depression in Hepatocellular Carcinoma Patients Treated with Transcatheter Arterial Chemoembolization: A Quasi-Experimental Study. Evidence-Based Complementary and Alternative Medicine, 2015, 1-10. https://doi.org/10.1155/2015/496485.

Lovejoy, R. (n.d.). Self-Care with Acupressure for Cancer-Related Fatigue | Natural Medicine Journal. Retrieved from https://www.naturalmedicinejournal.com/journal/2017-02/self-care-acupressure-cancer-related-fatigue.

Ma, H.-W., Chang, M.-L., \& Lin, C.-J. (2007). [A systematic review of acupressure for the application on nursing practice]. Hu li za zhi The journal of nursing, 54(4), 35-44. Retrieved from http://www.ncbi.nlm.nih.gov/pubmed/17654426. 
Mehling, W., E., Lown, E., A., Dvorak, C., C., Cowan, M., J., Horn, B., N., Dunn, E., A., \& Hecht, F., M. (2012). Hematopoietic Cell Transplant and Use of Massage for Improved Symptom Management: Results from a Pilot Randomized Control Trial. Evidence-Based Complementary and Alternative Medicine, 2012, 1-9. https://doi.org/10.1155/2012/450150.

Mehta, P., Dhapte, V., Kadam, S., \& Dhapte, V. (2017). Contemporary acupressure therapy: Adroit cure for painless recovery of therapeutic ailments. Journal of traditional and complementary medicine, 7(2), 251-263. https://doi.org/10.1016/j.jtcme.2016.06.004.

Mokhtari, R., B., Homayouni, T., S., Baluch, N., Morgatskaya, E., Kumar, S., Das, B., \& Yeger, H. (2017). Combination therapy in combating cancer. Oncotarget, 8(23), 38022-38043. https://doi.org/10.18632/oncotarget.16723.

Pearce, A., Haas, M., Viney, R., Pearson, S.-A., Haywood, P., Brown, C., \& Ward, R. (2017). Incidence and severity of self-reported chemotherapy side effects in routine care: A prospective cohort study. PLOS ONE, 12(10), e0184360. https://doi.org/10.1371/journal.pone.0184360.

Ryan, J., L., Carroll, J., K., Ryan, E., P., Mustian, K., M., Fiscella, K., \& Morrow, G., R. (2007). Mechanisms of Cancer-Related Fatigue. The Oncologist, 12(suppl_1), 22-34. https://doi.org/10.

Sabouhi, F., Kalani, L., Valiani, M., Mortazavi, M., \& Bemanian, M. (2013). Effect of acupressure on fatigue in patients on hemodialysis. Iranian journal of nursing and midwifery research, 18(6), 429-434. Retrieved from http://www.ncbi.nlm.nih.gov/pubmed/24554938.

Tournaire, M., \& Theau-Yonneau, A. (2007). Complementary and alternative approaches to pain relief during labor. Evidence-based complementary and alternative medicine: eCAM, 4(4), 409-417. https://doi.org/10.1093/ecam/nem012.

Werdani, Y., D., W. (2018). Effect of Cancer Related Fatigue tTo the Level of Independence of Cancer Patients and Caregiver Stress Level. Folia Medica Indonesiana, 54(2), 108. https://doi.org/10.20473/fmi.v54i2.8859.

Zick, S., M., Alrawi, S., Merel, G., Burris, B., Sen, A., Litzinger, A., \& Harris, R., E. (2011). Relaxation acupressure reduces persistent cancer-related fatigue. Evidence-based complementary and alternative medicine : eCAM, 2011. https://doi.org/10.1155/2011/142913.

Zick, S., M., Sen, A., Wyatt, G., K., Murphy, S., L., Arnedt, J., T., \& Harris, R., E. (2016). Investigation of 2 Types of Self-administered Acupressure for Persistent Cancer-Related Fatigue in Breast Cancer Survivors. JAMA Oncology, 2(11), 1470. https://doi.org/10.1001/jamaoncol.2016.1867.

Zick, S., M., Wyatt, G., K., Murphy, S., L., Arnedt, J., T., Sen, A., \& Harris, R., E. (2012). Acupressure for persistent cancer-related fatigue in breast cancer survivors (AcuCrft): a study protocol for a randomized controlled trial. BMC Complementary and Alternative Medicine, 12(1), 1118. https://doi.org/10.1186/1472-6882-12-132. 